\title{
Correspondence
}

\section{A multidisciplinary approach to intensive care medicine}

RAMON PEYRO, PABLO MONEDERO, THE EXECUTIVE COMMITTEE OF THE INTENSIVE CARE SECTION OF THE SPANISH SOCIETY OF ANAESTHESIOLOGY PUBLISHED WITH PERMISSION (EUROPEAN JOURNAL OF ANAESTHESIOLOGY 2012, 29:109-110)

\begin{abstract}
From the Servicio de Anestesia, Complejo Hospitalario Universitario de Albacete, Albacete (RP) and Departamento de Anestesia y Cuidados Intensivos, Clínica Universidad de Navarra, Pamplona (PM), Spain

Correspondence to Pablo Monedero, Clínica Universidad de Navarra, Avenida de P'o XII 36, 31008 Pamplona, Spain Tel: +34 948255 400; fax: +34 948172 294; e-mail: pmonedero@unav.es
\end{abstract}

The executive committee of the Intensive Care Section of the Spanish Society of Anaesthesia would like to thank Van Aken et al. ${ }^{1}$ for their editorial in favour of a multidisciplinary approach to intensive care medicine (ICM). The editorial is timely and highly needed in these times of increasing pressure for the recognition of a primary speciality of ICM in Europe. ${ }^{2}$ The arguments in the editorial against this proposal can be further expanded considering the situation of ICM in Spain and Europe.

In Spain, we have the broadest and longest European experience of a primary speciality in ICM. Other countries can learn from our bad experiences in order not to repeat our mistakes. The existence of a primary speciality constitutes an obstacle against the multidisciplinary access to ICM, because primary intensivists try to achieve exclusive attention over the critical patient. They progressively extend their scope of action, ${ }^{3}$ coming into conflict with anaesthesiologists in post-operative care, cardiologists in coronary units, emergency physicians, pneumologists and so on.

The existence of a primary speciality of ICM in Spain has meant an impoverishment in the training of all the specialities involved in the attention of critical patients, particularly anaesthesia. Training in anaesthesia has been limited to only 4 years to the detriment of ICM training, compromising the acquisition of competencies during the period of residency. Although more than $41 \%$ of intensive care beds in Spain are under anaesthesia-intensivists, ${ }^{4}$ since 2009 training in ICM during anaesthesia residency lasts only for a minimum of 6 months, up from 3 months previously. This inappropriate situation has become possible, as ICM has become a primary speciality. Anaesthesia-intensivists now need to make an extra effort in order to acquire competency in ICM. Competencies for ICM have been cut down on all primary specialities that attend critically ill patients and training in this field is practically nonexistent in Spain.

The Spanish system is inefficient, and probably not sustainable, due to the duplication of services, huge staffing, conflicts and rivalries not only in new openings but also in almost all hospitals where primary intensivists try to extend their dominance. Spanish primary intensivists have started to perform sedation for endoscopies and to control post-anaesthesia care units in small hospitals to increase their numbers and gain access to private practice.

The situation of medical specialities in Europe also advises against the recognition of a new primary speciality. In Europe there are 72 different primary specialities, including ICM. Only 48 of them are recognised by the European Union because they exist in at least two fifths of the countries, and ICM is not one of them. The European Union of Medical Specialists (UEMS) recognises few, only 38 specialities existing in at least one third of the member states. European recommendations for free movement of professionals require progressive unification with a reduction in the number of medical specialities. ${ }^{5}$ We must stop fragmenting an already over fragmented system. Recognition of a focused practice does not require the creation of a new primary speciality. The road map for the recognition of ICM as a particular competence is the most appropriate way not to make the present problem worse. ${ }^{6}$

The question is not on the convenience of a new primary speciality but on whether we need a multidisciplinary access for ICM. Those who defend a primary speciality are in fact rejecting a multidisciplinary access to ICM. The key aspects of ICM are not speciality-unique. The Competency-Based Training in Intensive Care Medicine (CoBaTrICe) program allows education and certification in a speciality -independent fashion, so that multiple speciality trainees can receive inter-speciality education. A multidisciplinary approach allows faculty and trainees to learn from counterparts outside of their base speciality.

Anaesthesia specialists had the generosity and broad outlook to recognise ICM as part of the training and work of different primary specialities through the creation of the UEMS Multidisciplinary Joint Committee of Intensive Care Medicine (MJCICM). However, if this multidisciplinary access is not recognised due to the expansion of a primary speciality, we claim that ICM belongs to anaesthesia. Historically, ICM is a sub-speciality of anaesthesia and anaesthesia is the primary speciality with most affinity and similarity to ICM. ${ }^{1}$ In fact, the new postgraduate UEMS/European Board of Anaesthesia (EBA) training guidelines identify medical and perioperative care of critically ill patients - general intensive care - as one of the 10 domains of general core competencies of anaesthesia training.?

In summary, the proposal to expand a primary speciality in Europe will not improve ICM and, instead, will create a barrier to the multidisciplinary approach to ICM. In that case, it would be preferable to expand anaesthesia sub-specialisation in ICM, as it already is in 17 European countries. ${ }^{1}$ 


\section{Acknowledgements}

No financial support or sponsorship was received. None of the authors has any conflict of interest.

The members of the executive committee of the Intensive Care Section of the Spanish Society of Anaesthesiology are as follows: R.P., Servicio de Anestesia, Complejo Hospitalario Universitario de Albacete, Albacete; P.M., Departamento de Anestesia y Cuidados Intensivos, Clínica Universidad de Navarra, Pamplona; Luciano Aguilera, Servicio de Anestesia, Hospital de Basurto, Bilbao; Fernando Barturen, Servicio de Anestesia, Hospital Universitari Son Espases, Palma Mallorca; Jaume Canet, Servicio de Anestesia, Hospital Universitari Germans Trias i Pujol, Badalona; Vicente Ginesta, Servicio de Anestesia, Complejo Hospitalario Universitario de Santiago de Compostela, Santiago de Compostela; Jose I. Gomez-Herreras, Servicio de Anestesia, Hospital Clínico Universitario de Valladolid, Valladolid; Juan Navia, Servicio de Anestesia, Hospital General Universitario Gregorio Maraòûn, Madrid; and Calixto Sanchez-Perez, Servicio de Anestesia, Hospital de Elda, Elda, Spain.

\section{References}

1 Van Aken H, Mellin-Olsen J, Pelosi P. Intensive care medicine: a multidisciplinary approach!. Eur J Anaesthesiol 2011; 28:313-315.

2 Moreno RP, Rhodes A. Intensive care medicine: a specialty coming to LIFE. Lancet 2010; 376:1275-1276.

3 Cabré L, Mancebo J, Blanch L. Intensive Care in Spain. Réanimation 2005; 14:24-35.

4 Monedero P. Presence of anaesthetists in intensive care medicine in Spain. Intensive Care Med 2010; 36:171.

5 European Union of Medical Specialists. UEMS policy proposals for classification and training durations of specialties registered in doctors directives 1996. Brussels: European Union of Medical Specialists; 1996. http://www.uems.net/uploadedfiles/42.pdf. [Accessed 27 April 2011]

6 European Society of Intensive Care Medicine. Road map to incorporate intensive care medicine in the directive 2005/36/EV of the European parliament and of the council on the recognition of professional qualifications as a particular medical competence in Europe in Annex 5.1.3. Titles of training courses in specialized medicine. 2008. http://ebicm.esicm.org/ road-map/. [Accessed 27 April 2011]

7 European Union of Medical Specialists, European Board of Anaesthesia. UEMS/EBA guidelines postgraduate training program in anaesthesiology, pain and intensive care medicine. 